\title{
Gold Nanorods Capped with Different Ammonium Bromide Salts on the Catalytic Chemical Reduction of $p$-Nitrophenol
}

\author{
Francyelle M. de Oliveira, ${ }^{\oplus a}$ Lucas R. B. A. Nascimento, ${ }^{\circledR a}$ Claudia M. S. Calado, ${ }^{\odot a}$ \\ Simoni M. P. Meneghetti, ${ }^{\circledR a}$ Monique G. A. da Silva ${ }^{\circledR} *, a$ and Mario R. Meneghetti ${ }^{\circledR} *, a$ \\ ${ }^{a}$ Grupo de Catálise e Reatividade Química, Instituto de Química e Biotecnologia, \\ Universidade Federal de Alagoas, Av. Lourival de Melo Mota s/n, Cidade Universitária, \\ 57072-900 Maceió-AL, Brazil
}

\begin{abstract}
It is known that the reactivity of the nanocatalytic systems is related to the particle size and shape and also to the features of the capping agents on the nanostructures. In this study, gold nanorods (AuNRs) were synthesized by the seed-mediated method using different tetraalkylammonium bromide salts as capping agents, that are, cetyltrimethylammonium (CTABr), $N, N$-dimethyl- $N$-cetyl- $N$-(2-hydroxyethyl)ammonium (HEA16Br), and $N, N$-dimethyl- $N$-cetyl$N$-(2-hydroxypropyl)ammonium (HPA16Br), and used as catalyst for the chemical reduction of $p$-nitrophenol (PNP) in the presence of $\mathrm{NaBH}_{4}$. The catalytic systems were characterized by ultraviolet-visible (UV-Vis) absorption spectroscopy and transmission electron microscopy (TEM). The effect of the ammonium bromide-based capping agent on the catalytic activity of AuNRs was evaluated by performing the chemical reduction of $p$-nitrophenol in the presence of excess $\mathrm{NaBH}_{4}$ in aqueous medium. Under the reaction conditions employed, the catalytic systems displayed detectable subtle differences in terms of induction times and apparent activation energy $\left(E_{a}\right)$ values. These results show that slight changes carried out in the chemical structure of the capping agent are able to imprint even slightly modification of the kinetic parameter of the catalytic reaction.
\end{abstract}

Keywords: gold nanorods, capping agents, ammonium salts, catalytic chemical reduction, p-nitrophenol

\section{Introduction}

In contrast to the bulk form, gold in nanometric scale presents particular chemical properties and can even be employed as a catalyst in important chemical reactions, ${ }^{1,2}$ such as $\mathrm{C}-\mathrm{C}$ and $\mathrm{C}-\mathrm{Het}$ bond formation, ${ }^{3,4}$ oxidation, ${ }^{5,6}$ hydrogenation ${ }^{7}$ and chemical reduction..$^{8-10}$ The catalytic activity of gold nanoparticles (AuNPs) is related not only to the large number of atoms present on the surface of the nanoparticles, i.e., large surface/volume ratios, ${ }^{11}$ but also to singular properties of these particles that arise due to quantum confinement. ${ }^{12}$ In the nanometric regime, both the surface/volume ratio and quantum confinement effects are strongly dependent on particle size ${ }^{13}$ and shape. ${ }^{14}$ Colloidal solutions of AuNPs with different sizes and shapes, for instance, display completely different optical properties, with localized surface plasmon resonances (LSPR) that can cover the whole visible spectrum..$^{15,16}$ This set of properties that arises in the nanometric scale ("nano effect")

*e-mail:mrm@qui.ufal.br; monique.silva@iqb.ufal.br is sometimes observed in nanocatalysis, mainly in the case of metal nanoparticles. ${ }^{17,18}$ For instance, nanoparticles with different shapes but approximately with the same number of atoms present different catalytic reactivities, since the number of exposed atoms per particle is shape-dependent. ${ }^{19}$ Moreover, only AuNPs with diameters between 1 and $10 \mathrm{~nm}$ are able to effectively promote $\mathrm{CO}$ oxidation. ${ }^{5,6}$

Another important feature that must be considered in relation to catalytic systems based on nanoparticles is the nature of the molecules used to surround the nanoparticles, to prevent agglomeration in colloidal suspensions..$^{20}$ Indeed, these molecules (capping agents) play an important role in the catalytic properties of the particle, since, in general, the reagents need to pass through this molecular layer to have access to the catalytic surface. ${ }^{21-24}$

Chemical reduction catalyzed by AuNPs in the presence of hydrogen molecules is now possible, but the applications are restricted, since gold surfaces have limited ability to adsorb and activate hydrogen and thus harsh reaction conditions may be required, i.e., high temperatures and pressures. ${ }^{25-27}$ On the other hand, the very efficient 
chemoselective reduction of nitroarene compounds to the respective amines ${ }^{28}$ catalyzed by AuNPs, using $\mathrm{NaBH}_{4}$ as a reducing agent, ${ }^{29}$ is extensively described in the literature. This chemical transformation is applied in the fine chemicals industry, for example, in the manufacture of analgesic and antipyretic drugs, corrosion inhibitors, etc. ${ }^{30,31}$ In this context, $p$-nitrophenol (PNP) is frequently used as a model substrate to compare and evaluate the potential of reducing agents and catalysts for the chemical reduction of nitroarene to aminoarene compounds. ${ }^{32}$

The catalytic reduction of PNP meets all criteria for adoption as a model catalytic reaction, preferably under aqueous conditions and at close to room temperature. . $^{33,34}$ The evaluation of the catalytic reduction of PNP in the presence of AuNPs has been reported considering the different aspects of the catalytic systems, such as particle size/surface area, ${ }^{35,36}$ morphology,${ }^{15}$ facets, ${ }^{37}$ and active site requirements. ${ }^{38}$ Also, several authors ${ }^{39,40}$ have compared the catalytic activity of colloidal gold nanoparticles with different capping agents and ligands. The structural aspects of the nanoparticle as well as the capping agents are the main aspects that can modulate the reactivity of the nanocatalyst. Recently, we reported the catalytic activity of AuNPs with different morphologies but the same capping agent in the chemical reduction of PNP. ${ }^{16}$

In the study reported herein, we prepared catalytic systems based on gold nanorods (AuNRs) with different capping agents based on ammonium bromide and compered their catalytic properties on the reduction of $p$-nitrophenol (PNP) to $p$-aminophenol (PAP) under the same number of catalytic nanoparticles. This is the right condition to analyze the effect of similar capping agents and determine which is the suitable agent for the reaction.

\section{Experimental}

\section{Materials}

$\mathrm{HAuCl}_{4} .3 \mathrm{H}_{2} \mathrm{O}(99.9 \%), \mathrm{NaBH}_{4}(99 \%),(+)$-L-ascorbic acid $(99 \%)$, cetyltrimethylammonium bromide (CTABr, $98 \%$ ), and $\mathrm{AgNO}_{3}(99 \%)$ were obtained from Sigma-Aldrich (St. Louis, USA) and used as purchased. Deionized water was used to prepare all aqueous solutions. All reactions were conducted in the presence of air. N,N-Dimethyl- $N$-cetyl$N$-(2-hydroxyethyl)ammonium bromide (HEA16Br) and $N, N$-dimethyl- $N$-cetyl- $N$-(2-hydroxypropyl)ammonium bromide (HPA16Br) were prepared as previously described. ${ }^{24} \mathrm{UV}-\mathrm{Vis}$ spectra were recorded on a Shimadzu UV-2600 (Kyoto, Japan), with the aid of a temperaturecontrolled cell, Shimadzu CPS-100 (Kyoto, Japan) and optical glass cells with a length of $1.0 \mathrm{~cm}$. The set-up was configured to fix the baseline of the distilled water absorption band from 390 to $410 \mathrm{~nm}$. Transmission electron microscopy (TEM) was performed on a FEI Tecnai 20 electron microscope (Hillsboro, USA) at an accelerating voltage of $120 \mathrm{kV}$, and the samples were prepared with the addition of a drop of the gold colloidal solution on a copper grid coated with a porous carbon film. The hydroxylated ammonium salts were readily synthesized in one-step procedure described by Roucoux and co-workers. ${ }^{24}$ Briefly, for HEA16Br, $15 \mathrm{~mL}$ of ethanol, $10.7 \mathrm{~mL}$ of bromohexadecane, and $3 \mathrm{~mL}$ of $2-(N, N$-dimethylamino) ethanol were placed in a two-necked flask maintained under reflux at $80{ }^{\circ} \mathrm{C}$ and left under stirring for $48 \mathrm{~h}$. The same procedure was performed for the synthesis of $\mathrm{HPA} 16 \mathrm{Br}$, in this case applying $3.5 \mathrm{~mL}$ of 3 -( $N, N$-dimethylamino)1-propanol.

\section{Synthesis of gold nanorods}

The AuNRs-based catalysts were prepared by the seedmediated method, adapted from the protocols developed in the literature. ${ }^{41,42}$ Briefly, two solutions were initially prepared: ( $i$ ) seed solution: in a $25 \mathrm{~mL}$ flask, an aqueous solution of $0.025 \mathrm{~mol} \mathrm{~L}^{-1} \mathrm{HAuCl}_{4}(0.1 \mathrm{~mL} ; 0.0025 \mathrm{mmol})$ was mixed with an aqueous solution of $0.067 \mathrm{~mol} \mathrm{~L}^{-1} \mathrm{CTABr}$ (7.4 mL; $0.5 \mathrm{mmol})$. An ice-cold aqueous solution of $0.01 \mathrm{~mol} \mathrm{~L}^{-1} \mathrm{NaBH}_{4}(0.6 \mathrm{~mL} ; 0.006 \mathrm{mmol})$ was then added and the color of the solution immediately turned brown. After $2 \mathrm{~min}$, the system was left for at least $2 \mathrm{~h}$ without stirring prior to use; and (ii) growth solution: in a $25 \mathrm{~mL}$ flask, an aqueous solution of $0.025 \mathrm{~mol} \mathrm{~L}^{-1} \mathrm{HAuCl}_{4}(0.2 \mathrm{~mL} ; 0.005 \mathrm{mmol})$ was added to a $0.068 \mathrm{~mol} \mathrm{~L}^{-1}$ aqueous solution of the respective surfactant ( $7.3 \mathrm{~mL} ; 0.5 \mathrm{mmol})$. In the next step, $0.15 \mathrm{~mL}$ of an aqueous solution of $0.004 \mathrm{~mol} \mathrm{~L}^{-1} \mathrm{AgNO}_{3}(0.15 \mathrm{~mL})$ was added under stirring, followed by the addition of an aqueous solution of $0.0788 \mathrm{~mol} \mathrm{~L}^{-1}$ ascorbic acid $(0.070 \mathrm{~mL})$. The system became colorless, verifying the reduction of $\mathrm{Au}^{3+}$ to $\mathrm{Au}^{+}$. The growth of the nanoparticles was initiated by the addition of an aliquot $(0.060 \mathrm{~mL})$ of the seed solution to the freshly prepared growth solution. The solution was kept briefly under stirring (10 s) and then allowed to stand for at least $4 \mathrm{~h}$ without stirring. Before the application of the nanoparticles in the catalytic reactions (within $24 \mathrm{~h}$ ), the AuNRs obtained were separated by centrifugation (13500 rpm, $15 \mathrm{~min}, 25^{\circ} \mathrm{C}$ ) and redispersed in deionized water $(8.0 \mathrm{~mL})$.

\section{Chemical reduction reactions}

All reactions were carried out in a $4 \mathrm{~mL}$ glass optical cuvette. At different temperatures $(20,25,30,35$, 
$40,45,50$ and $55^{\circ} \mathrm{C}$ ), the reagents were added in the following sequence: $2.0 \mathrm{~mL}$ of the PNP aqueous solution $\left(1.0 \mathrm{mmol} \mathrm{L}^{-1}\right), 1.0 \mathrm{~mL}$ of the aqueous solution of $\mathrm{NaBH}_{4}$ at specific concentrations $\left(0.25 \mathrm{~mol} \mathrm{~L}^{-1}\right)$, and $0.05 \mathrm{~mL}$ of the AuNR solution $\left(0.2 \mathrm{mmol} \mathrm{L}^{-1}\right)$. The catalytic conversion of PNP was then analyzed by UV-Vis spectroscopy.

\section{Results and Discussion}

We carried out a systematic study of reactions for the chemical reduction of PNP in the presence of $\mathrm{NaBH}_{4}$ and AuNRs capped with three different capping agents based on the ammonium bromide salts, CTABr, HEA16Br and HPA16Br (see Figure 1), as catalysts. Based on these experiments, physical-chemical parameters, such as apparent rate constant $\left(\mathrm{k}_{\mathrm{app}}\right)$ and apparent activation energy $\left(E_{\mathrm{a}}\right)$, were obtained for all of the reaction systems.

In the presence of these three surfactants, we prepared three colloidal AuNR@ammonium bromide salts via the seed-mediated method, using the approach developed by Nikoobakht and El-Sayed. ${ }^{41}$ The colloids obtained were characterized by UV-Vis spectroscopy and their particles were analyzed by TEM (Figure 2). The three absorption spectra presented in Figure 2a are typical of systems containing colloidal AuNR, i.e., showing two maximum absorption bands $\left(\lambda_{\max }\right) \cdot{ }^{41} \mathrm{In}$ the three cases, the maximum absorption bands are around 515 and $700 \mathrm{~nm}$, suggesting that the AuNRs formed in all systems present similar aspect ratios. ${ }^{43}$ It worth mentioning here that the slightly difference

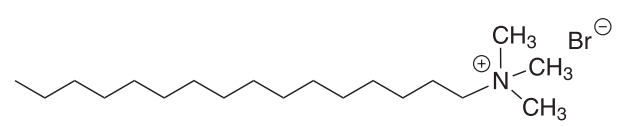

Cetyltrimethylammonium bromide $(\mathrm{CTABr})$

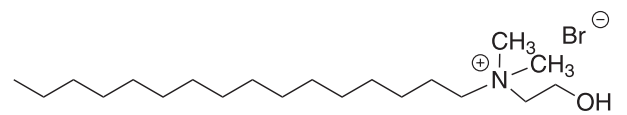

$N, N$-dimethyl- $N$-cetyl- $N$-(2-hydroxyethyl)ammonium bromide (HEA16Br)

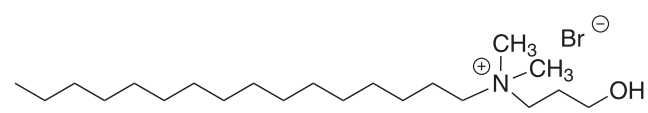

$N, N$-dimethyl- $N$-cetyl- $N$-(2-hydroxypropyl)ammonium bromide (HPA16Br)

Figure 1. Chemical structures of the capping C16 ammonium bromide salts employed.

between the three extinction spectra, mainly in the second maximum absorption band $\left(\lambda_{\max 2}\right)$, can be due to: $(i)$ the small differences in the aspect ratio of the AuNRs produced in each system; and (ii) the slight difference in the nature of the chemical molecular structure of the capping agents (see Figure 1). ${ }^{44}$ The TEM images confirmed the formation of AuNRs with similar dimensions, i.e., approximately $30 \times 10 \mathrm{~nm}$ (aspect ratio 3.0). In the three colloids, it was found approximately the same number of quasi-spherical particles (ca. 15\%), normally generated using this method. ${ }^{45}$

For the catalytic reaction, it is important to note that in our study we assumed that the same number of particles of AuNRs were added to the reaction mixtures, since for each colloidal solution the same number of seed particles (that
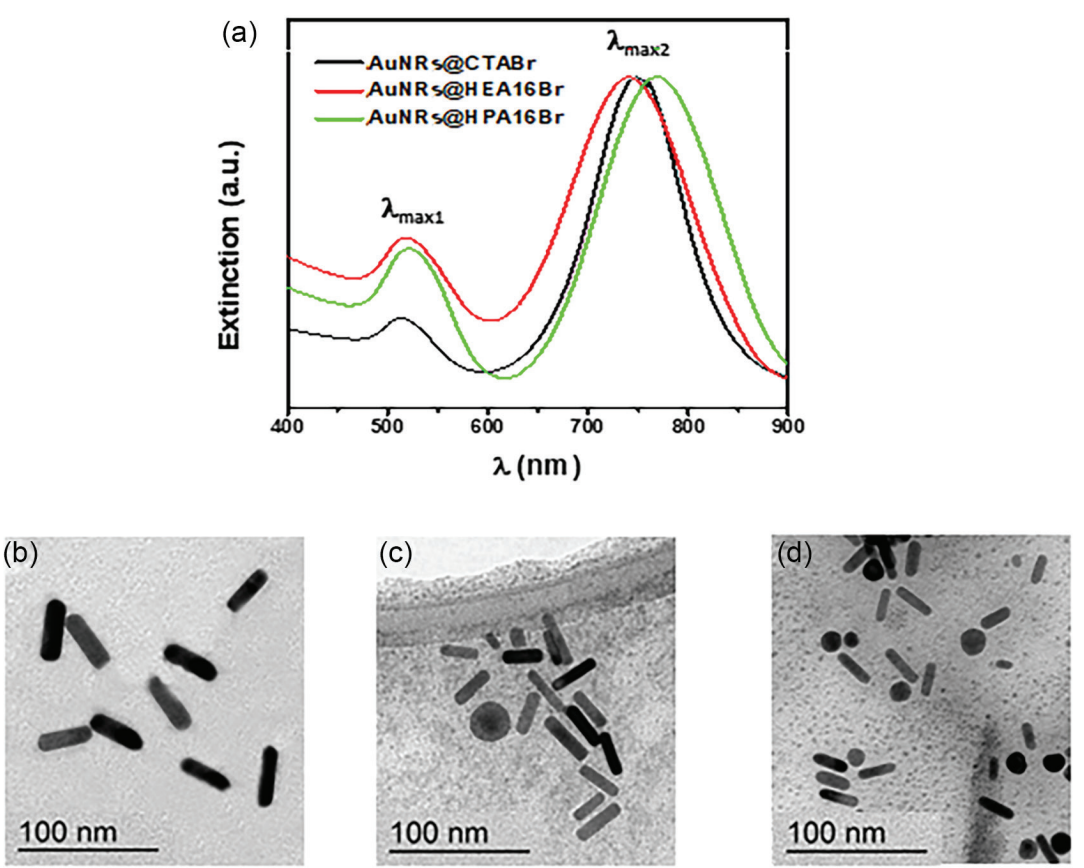

Figure 2. (a) Extinction spectra for the colloids AuNR@CTABr, AuNR@HEA16Br, and AuNR@HPA16Br. TEM images of the respective colloidal particles (b) AuNR@CTABr, (c) AuNR@HEA16Br, and (d)AuNR@HPA16Br. 
grow and form AuNRs) was added. This control ensured that the number of particles formed in the three colloidal solutions is practically the same.

Prior to the catalytic reactions, all AuNPs were isolated from the mother colloidal solution to eliminate the excess of capping agent and all traces of soluble gold species, which can interfere in the catalytic process. ${ }^{46,47}$

The catalytic reduction of the $p$-nitrophenol (PNP) to $p$-aminophenol (PAP) by $\mathrm{NaBH}_{4}$ was chosen as a model reaction to evaluate the catalytic activity of the systems AuNR@CTABr, AuNR@HEA16Br and AuNR@HPA16Br. UV-Vis extinction spectra were recorded over time to follow the chemical reaction (Figure 3). In all cases, the maximum extinction band at $400 \mathrm{~nm}$ is related to the presence of the sodium salt of PNP, formed under alkaline conditions soon after the addition of $\mathrm{NaBH}_{4}$, in the medium. At this moment, the color of the mixture changes immediately from light to bright yellow. The chemical reduction initiates only after the addition of the catalyst (AuNRs) in the reactor, easily confirmed by a change in the color of the solution, from bright yellow to colorless (Figure 3a) and measured by the decrease in the band of the ionic form of PNP

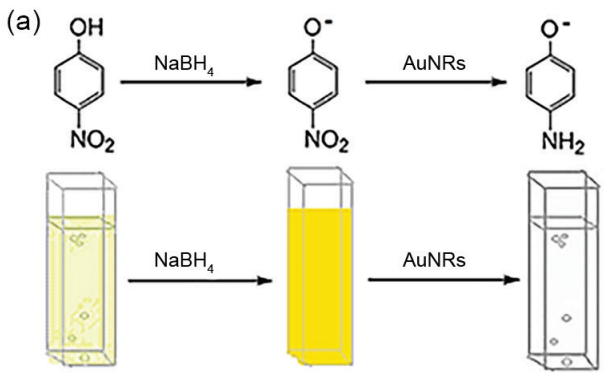

$(400 \mathrm{~nm})$ and a new weak band at $300 \mathrm{~nm}$ appears due to the formation of the reaction product, i.e., the ionic form of PAP (Figure 3b). ${ }^{48,49}$

In order to obtain the kinetic parameters related to the chemical reduction of PNP for the three catalytic systems, we carried out a series of catalytic reactions at different temperatures. These data can be used to evaluate the relationship between the nature of the AuNR capping agent and the catalytic activity of the systems for the chemical reduction of PNP to PAP.

Since the catalytic reactions occur in a pseudo-firstorder reaction regime, because the concentration of sodium borohydride employed was much higher than the stoichiometric amount needed to reduce PNP, ${ }^{50}$ it was reasonable to assume that the concentration of $\mathrm{BH}_{4}$ remained constant during the reaction. Plots of $\ln [\mathrm{PNP}]-\ln [\mathrm{PNP}]_{0}$ versus reaction time show linearity for the three catalytic systems (see Supplementary Information section for details), and from the slope of the line we obtained the $\mathrm{k}_{\text {app }}$ for each reaction, ${ }^{51}$ as summarized in Table 1.

From the data in Table 1, it can be observed that the apparent rate constant for the reaction catalyzed by

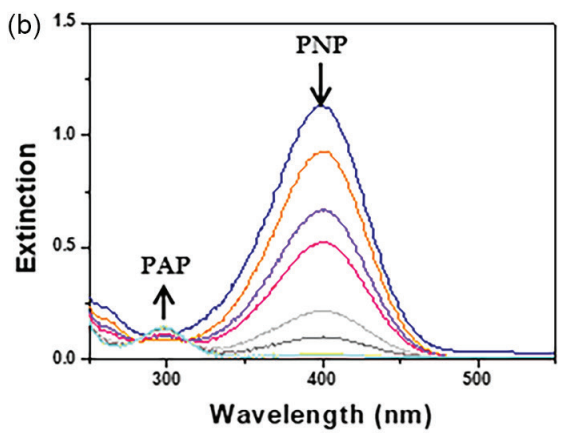

Figure 3. (a) General representation of catalytic chemical reduction of the nitro functional group of the $p$-nitrophenolate to $p$-aminophenolate in the presence of $\mathrm{NaBH}_{4}$ and AuNRs as catalysts; and (b) typical series of UV-Vis extinction spectra obtained during the catalytic chemical reduction of $p$-nitrophenol.

Table 1. Apparent rate constants $\left(\mathrm{k}_{\text {app }}\right)$ for the reactions carried out at different temperatures for the catalytic systems AuNR@HEA16Br, AuNR@HPA16Br and AuNR@CTABr

\begin{tabular}{|c|c|c|c|c|c|c|}
\hline \multirow{2}{*}{ Temperature $/{ }^{\circ} \mathrm{C}$} & \multicolumn{2}{|c|}{ AuNR@CTABr } & \multicolumn{2}{|c|}{ AuNR@HEA16Br } & \multicolumn{2}{|c|}{ AuNR@HPA16Br } \\
\hline & $\mathrm{k}_{\mathrm{app}} / \mathrm{s}^{-1}$ & Error & $\mathrm{k}_{\mathrm{app}} / \mathrm{s}^{-1}$ & Error & $\mathrm{k}_{\mathrm{app}} / \mathrm{s}^{-1}$ & Error \\
\hline 20 & 0.118 & \pm 0.076 & 0.109 & \pm 0.043 & 0.055 & \pm 0.034 \\
\hline 25 & 0.204 & \pm 0.024 & 0.180 & \pm 0.034 & 0.125 & \pm 0.036 \\
\hline 30 & 0.387 & \pm 0.108 & 0.271 & \pm 0.034 & 0.184 & \pm 0.059 \\
\hline 35 & 0.445 & \pm 0.045 & 0.331 & \pm 0.073 & 0.235 & \pm 0.066 \\
\hline 40 & 0.473 & \pm 0.059 & 0.378 & \pm 0.045 & 0.345 & \pm 0.053 \\
\hline 45 & 0.625 & \pm 0.145 & 0.496 & \pm 0.078 & 0.384 & \pm 0.033 \\
\hline 50 & 0.753 & \pm 0.103 & 0.649 & \pm 0.098 & 0.401 & \pm 0.057 \\
\hline 55 & 1.372 & \pm 0.209 & 1.043 & \pm 0.163 & 0.600 & \pm 0.078 \\
\hline
\end{tabular}

$\mathrm{k}_{\text {app }}$ : apparent rate constant; AuNRs: gold nanorods; CTABr: cetyltrimethylammonium; HEA16Br: $N, N$-dimethyl- $N$-cetyl- $N$-(2-hydroxyethyl)ammonium; HPA16Br $N, N$-dimethyl- $N$-cetyl- $N$-(2-hydroxypropyl)ammonium. 
the system AuNR@HPA16Br has the lowest value for all reaction temperatures tested, and the highest values were attained when the catalytic system AuNR@CTABr was used. For these systems, the substrate must pass through the barrier formed by the capping agents (CTABr, HEA16Br, or HPA16Br) that surrounds the AuNRs, and we suggest that the access of the substrates to the gold surface is different for each system. It can be seen that the induction time verified before the PNP reduction reaction is in fact different for the three systems, mainly at lower reaction temperatures (see Table 2). The same trend observed for the reaction rate is once again verified for the induction time, i.e., the system AuNR@HPA16Br presented the longest induction period and AuNR @CTABr the shortest.

Table 2. Induction time for the reactions carried out at different temperatures for the catalytic systems AuNR@CTABr,AuNR@HEA16Br and AuNR@HPA16Br

\begin{tabular}{lccc}
\hline Temperature / & \multicolumn{3}{c}{ Induction time / s } \\
\cline { 2 - 4 }${ }^{\circ} \mathrm{C}$ & AuNR@CTABr & AuNR@HEA16Br & AuNR@HPA16Br \\
\hline 20 & 400 & 470 & 500 \\
25 & 330 & 340 & 400 \\
30 & 250 & 280 & 330 \\
35 & 200 & 200 & 280 \\
40 & 180 & 190 & 200 \\
45 & 150 & 165 & 170 \\
50 & 115 & 120 & 150 \\
55 & 75 & 85 & 100 \\
\hline
\end{tabular}

AuNRs: gold nanorods; CTABr: cetyltrimethylammonium; HEA16Br: $N, N$-dimethyl- $N$-cetyl- $N$-(2-hydroxyethyl)ammonium; HPA16Br: $N, N$-dimethyl- $N$-cetyl- $N$-(2-hydroxypropyl)ammonium.

The most important factors related to these differences are postulated as follows: $(i)$ the resistance of the capping agents, hindering the reagents ( $\mathrm{PNP}$ and $\mathrm{NaBH}_{4}$ ) from reaching the surface of the nanorods; ${ }^{52-54}$ and (ii) the release of the final product from the surface of the catalyst. All other factors can be considered at the same level for the three systems. ${ }^{55-57}$

At this point, it is worth mentioning how the molecular structure of the capping agents are arranged around the AuNRs. There are strong evidences that freshly prepared colloidal seed mediated AuNRs have a compact bilayer of CTABr capping the nanoparticle. ${ }^{47,58,59}$ However, in the reaction medium of catalytic tests employed in this work, this arrange can be destabilized leading to the formation of a less compact arrange of the capping agent, suggesting the formation of micellar structures anchored on the gold surface. ${ }^{47}$ However, in the presence of hydroxylated chains, as in the case of HEA16Br and HPA16Br, stronger intermolecular interactions, via hydrogen bonds, between the surfactant molecular structures must occur, hampering the adsorption of the reagents on the metallic surface of the particle, leading to longer induction times and slower reaction rates..$^{24,47}$ These hydrogen bond interactions seems to be more effective when the hydroxylated carbon chain is longer (HPA16Br).

The Arrhenius equation ${ }^{51}$ can then be used to obtain the $\mathrm{E}_{\mathrm{a}}$ value for the chemical reduction of PNP reactions using each catalytic system (see Figure 4), i.e., 41, 43, and $50 \mathrm{~J} \mathrm{~mol}^{-1} \mathrm{~K}^{-1}$ for the catalytic systems AuNR@CTABr, AuNR@HEA16Br, and AuNR@HPA16Br, respectively. These values are consistent with similar studies. ${ }^{19,60-62}$
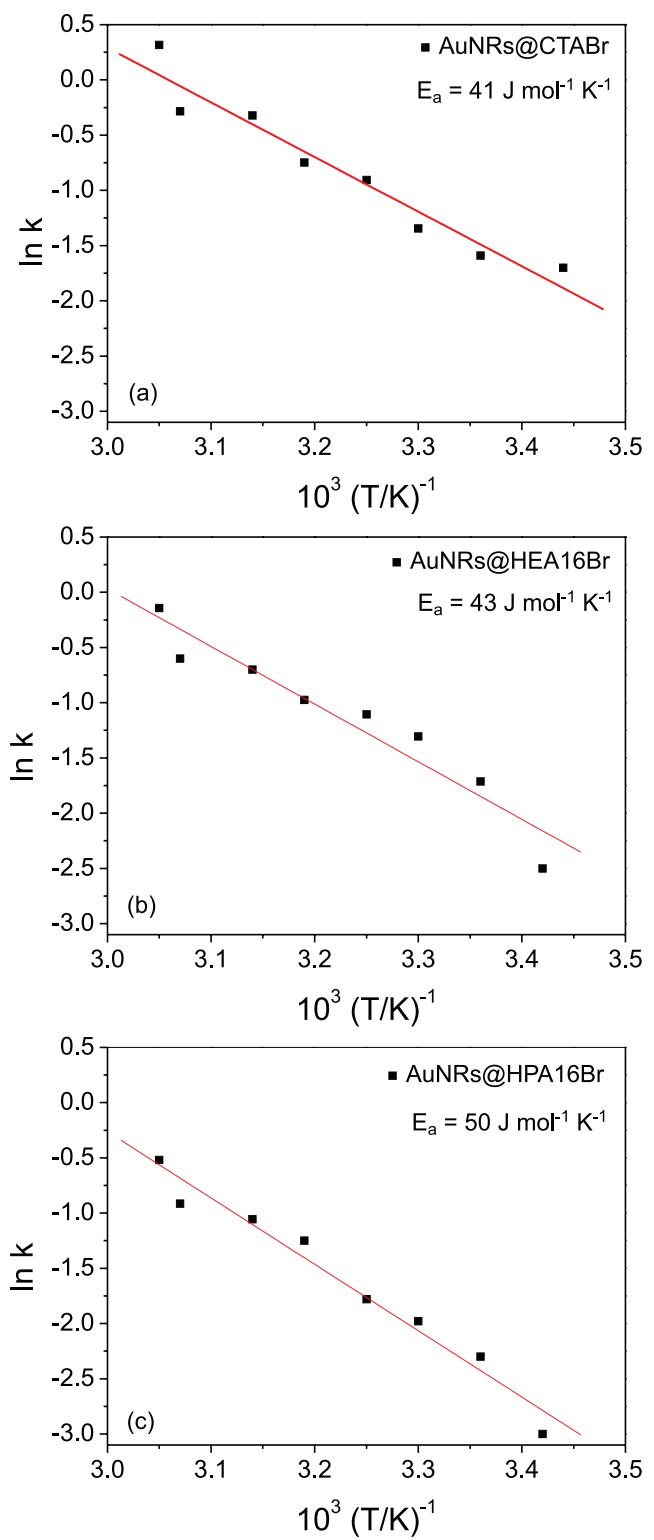

Figure 4. The respective Arrhenius law plots of $\mathrm{k}_{\text {app }}$ versus $1 / \mathrm{T}$ used to calculate the $\mathrm{E}_{\mathrm{a}}$ value from the linear slope for the reduction reaction of PNP catalyzed by (a) AuNR@CTABr; (b) AuNR@HEA16Br and (c) AuNR@HPA16Br. 


\section{Conclusions}

In this study we demonstrated that aqueous colloidal solutions based on AuNRs coated with hydroxylated ammonium salts, prepared by the seed-mediated method, were catalytically active in the conversion of PNP, producing PAP in the presence of $\mathrm{NaBH}_{4}$. Even though the amount of gold and number of particles were practically the same for the three catalytic systems evaluated, the catalytic properties differed. The reaction rates of the systems were very sensitive to the reaction temperature and in all cases, under the same reaction conditions, the values for the apparent rate constant $\left(\mathrm{k}_{\text {app }}\right)$ of the systems and, consequently, the apparent activation energy $\left(E_{a}\right)$ differed considerably. These results reinforce the fact that the nature of the capping agent must be considered in the evaluation of the catalytic properties. It is postulated that the main reason for these differences in the catalytic properties is the permeability of the double layer of the capping agents in relation to the reagents. It is possible that the capping agents bearing hydroxylated substituents generate more compact double layer structures, hindering the access of the reagents to the surface of the catalyst, i.e., the surface of the gold particle.

\section{Supplementary Information}

Supplementary information (plots of [PNP] versus time and $\ln [\mathrm{PNP}]-\ln [\mathrm{PNP}]_{0}$ versus time at different temperatures) is available free of charge at http://jbcs.sbq.org.br as PDF file.

\section{Acknowledgments}

The authors are grateful for the financial support of the following Brazilian research funding agencies: Conselho Nacional de Desenvolvimento Científico e Tecnológico (CNPq) project No. 408139/2018-8, Financiadora de Estudos e Projetos (FINEP), Fundação de Amparo à Pesquisa do Estado de Alagoas (FAPEAL), Coordenação de Aperfeiçoamento de Pessoal de Nível Superior (CAPES), and Instituto Nacional de Ciência e Tecnologia de Catálise em Sistemas Moleculares e Nanoestruturados (INCTCatálise). MRM is grateful to CNPq for a research fellowship and FMO acknowledges CAPES for scholarships. The authors are also grateful for the technical assistance of the Centro de Microscopia Eletrônica of the Federal University of Paraná, Brazil.

\section{Author Contributions}

Francyelle M. de Oliveira was responsible for investi- gation, methodology, writing-original draft, and writingreview and editing; Lucas R. B. A. Nascimento for investigation, writing-original draft, and writing-review and editing; Claudia M. S. Calado for investigation, writingoriginal draft, and writing-review and editing; Simoni M. P. Meneghetti for conceptualization, funding acquisition, investigation, and writing-review and editing; Monique G. A. da Silva for conceptualization, investigation, writingoriginal draft, and writing-review and editing; Mario R. Meneghetti for conceptualization, funding acquisition, investigation, methodology, project administration, writingoriginal draft, and writing-review and editing.

\section{References}

1. Ciriminna, R.; Falletta, E.; della Pina, C.; Teles, H. H.; Pagliaro, M.; Angew. Chem., Int. Ed. 2016, 55, 14210.

2. Ndolomingo, M. J.; Bingwa, N.; Meijboom, R.; J. Mater. Sci. 2020, 55, 6195.

3. Liu, X.; He, L.; Liu, Y.-M.; Cao, Y.; Acc. Chem. Res. 2014, 47, 793.

4. Li, G.; Jin, R.; Nanotechnol. Rev. 2013, 2, 529.

5. Ilieva, L.; Petrova, P.; Pantaleo, G.; Zanella, R.; Sobczak, J. W.; Lisowski, W.; Ivanov, I.; Kaszkur, Z.; Liotta, L. F.; Venezia, A. M.; Tabakova, T.; Catal. Today 2020, 357, 547.

6. Sun, K.; Chin. J. Catal. 2016, 37, 1608.

7. Silva, R. J. M.; Fiorio, J. L.; Vidinha, P.; Rossi, L. M.; J. Braz. Chem. Soc. 2019, 30, 2162.

8. Liu, Y.; Xu, L.; Liu, X.; Cao, M.; Catalysts 2016, 6, 3.

9. Zhao, Z. P.; Feng, X.; Huang, D.; Yang, G.; Astruc, D.; Coord. Chem. Rev. 2015, 287, 114.

10. Balakumar, V.; Kim, H.; Ryu, J. W.; Manivannan, R.; Son, Y.-A.; J. Mater. Sci. Technol. 2020, 40, 176.

11. Narayan, R.; El-Sayed, M. A.; J. Phys. Chem. B 2004, 108, 5726.

12. Barbry, M.; Koval, P.; Marchesin, F.; Esteban, R.; Borisov, A. G.; Aizpurua, J.; Sánchez-Portal, D.; Nano Lett. 2015, 15, 3410.

13. Panigrahi, S.; Basu, B.; Praharaj, S.; Pande, S.; Jana, S.; Pal, A.; Ghosh, S. K.; Pal, T.; J. Phys. Chem. C 2007, 111, 4596.

14. Burda, C.; Chen, X.; Narayanan, R.; El-Sayed, M. A.; Chem. Rev. 2005, 105, 1025.

15. Toma, H. E.; Zamarion, V. M.; Toma, S. H.; Araki, K.; J. Braz. Chem. Soc. 2010, 21, 1158.

16. de Oliveira, F. M.; Nascimento, L. R. B. A.; Calado, C. M. S.; Meneghetti, M. R.; Silva, M. G. A.; Catalysts 2016, 6, 215.

17. Yang, F.; Deng, D.; Pan, X.; Fu, Q.; Bao, X.; Natl. Sci. Rev. 2015, 2, 183.

18. Chen, W.; Lin, T.; Dai, Y.; An, Y.; Yu, F.; Zhong, L.; Li, S.; Sun, Y.; Catal. Today 2018, 311, 8. 
19. Ma, T.; Yang, W.; Liu, S.; Zhang, H.; Liang, F.; Catalysts 2017, 7,38 .

20. da Silva, J. A.; Dias, R. P.; da Hora, G. C. A.; Soares, T. A.; Meneghetti, M. R.; J. Braz. Chem. Soc. 2018, 29, 191.

21. Sharma, V.; Sundaramurthy, A.; ACS Omega 2019, 4, 628.

22. Jin, M.; Liu, H.; Zhang, H.; Xie, Z.; Liu, J.; Xia, Y.; Nano Res. 2011, 4, 83 .

23. Rossi, L. M.; Fiorio, J. L.; Garcia, M. A. S.; Ferraz, C. P.; Dalton Trans. 2018, 47, 5889.

24. Bilé, E. G.; Sassine, R.; Denicourt-Nowicki, A.; Launay, F.; Roucoux, A.; Dalton Trans. 2011, 40, 6524.

25. Mitsudome, T.; Kaneda, K.; Green Chem. 2013, 15, 2636.

26. Takale, B.; Bao, M.; Yamamoto, Y.; Org. Biomol. Chem. 2014, 12, 2005.

27. He, D.; Jiao, X.; Jiang, P.; Wang, J.; Xu, B.-Q.; Green Chem. 2012, 14, 111.

28. Sun, J.; Fu, Y.; He, G.; Sun, X.; Wang, X.; Catal. Sci. Technol. 2014, 4, 1742.

29. Monti, G. A.; Correa, N. M.; Falcone, R. D.; Silbestri, G. F.; Moyano, F.; RSC Adv. 2020, 10, 15065.

30. Mitchell, S.; Kirk-Othmer Encyclopedia of Chemical Technology, th $^{\text {th }}$ ed.; Wiley-Interscience: New York, 1992.

31. Bereket, G.; Duran, B.; Prog. Org. Coat. 2009, 64, 57.

32. Aditya, T.; Pal, A.; Pal, T.; Chem. Commun. 2015, 51, 9410.

33. Gu, S.; Wunder, S.; Lu, Y.; Ballauff, M.; J. Phys. Chem. C 2014, 118, 18618.

34. Hervés, P.; Pérez-Lorenzo, M.; Liz-Marzán, L. M.; Dzubiella, J.; Lu, Y.; Ballauff, M.; Chem. Soc. Rev. 2012, 41, 5577.

35. Fenger, R.; Fertitta, E.; Kirmse, H.; Thünemannc, A. F.; Rademann, K.; Phys. Chem. Chem. Phys. 2012, 14, 9343.

36. Kundu, S.; Lau, S.; Liang, H.; J. Phys. Chem. C 2009, 113, 5150.

37. Eo, M.; Baek, J.; Song, H. D.; Lee, S.; Yi, J.; Chem. Commun. 2013, 49, 5204.

38. Nigra, M. M.; Ha, J.-M.; Katz, A.; Catal. Sci. Technol. 2013, 11, 2976.

39. Ciganda, R.; Li, N.; Deraedt, C.; Gatard, S.; Zhao, P.; Salmon, L.; Hernández, R.; Ruiz, J.; Astruc, D.; Chem. Commun. 2014, 50, 10126.

40. Deraedt, C.; Salmon, L.; Gatard, S.; Ciganda, R.; Hernández, R.; Ruiz, J.; Astruc, D.; Chem. Commun. 2014, 50, 14194.

41. Nikoobakht, B.; El-Sayed, M. A.; Chem. Mater. 2003, 15, 1957.

42. Silva, M. G. A.; Nunes, Á. M.; Meneghetti, S. M. P.; Meneghetti, M. R.; C. R. Chim. 2013, 16, 640.
43. Perez-Juste, J.; Pastoriza-Santos, I.; Liz-Marzan, L. M.; Mulvaney, P.; Coord. Chem. Rev. 2005, 249, 1870.

44. Hana, C.; Qi, M.-Y.; Tanga, Z.-R.; Gong, J.; Xua, Y.-J.; Nano Today 2019, 27, 48.

45. Silva, M. G. A.; Meneghetti, M. R.; Denicourt-Nowicki, A.; Roucoux, A.; RSC Adv. 2013, 3, 18292.

46. Orendorff, C. J.; Murphy, C. J.; J. Phys. Chem. B 2006, 110, 3990.

47. Silva, J. A.; Meneghetti, M. R.; Langmuir 2018, 34, 366.

48. Layek, K.; Kantam, M. L.; Shirai, M.; Nishio-Hamane, D.; Sasakid, T.; Maheswaran, H.; Green Chem. 2012, 14, 3164.

49. Li, F.; Li, Z.; Zeng, C.; Hu, Y.; J. Braz. Chem. Soc. 2017, 28 , 960.

50. Nandanwar, S. U.; Chakraborty, M.; Chin. J. Catal. 2012, 33, 1532.

51. Atkins, P.; Paula, J.; Physical Chemistry, $8^{\text {th }}$ ed.; W. H. Freeman and Company: Oxford, 2006.

52. Suchomel, P.; Kvitek, L.; Prucek, R.; Panacek, A.; Halder, A.; Vajda, S.; Zboril, R.; Sci. Rep. 2018, 8, 4589.

53. Wunder, S.; Polzer, F.; Lu, Y.; Mei, Y.; Ballauff, M.; J. Phys. Chem. C 2010, 114, 8814.

54. Yamamoto, H.; Yano, H.; Kouchi, H.; Obora, Y.; Arakawa, R.; Kawasaki, H.; Nanoscale 2012, 4, 4148.

55. Strachan, J.; Barnett, C.; Masters, A. F.; Maschmeyer, T.; ACS Catal. 2020, 10, 5516.

56. Zhou, X.; Xu, W.; Liu, G.; Panda, D.; Chen, P.; J. Am. Chem. Soc. 2010, 132, 138.

57. Mei, Y.; Lu, Y.; Polzer, F.; Ballauff, M.; Chem. Mater. 2007, 19, 1062 .

58. Murphy, C. J.; Sau, T. K.; Gole, A. M.; Orendorff, C. J.; Gao, J.; Gou, L.; Hunyadi, S. E.; Li, T.; J. Phys. Chem. B 2005, 109, 13857.

59. Silva, J. A.; Netz, P. A.; Meneghetti, M. R.; Langmuir 2020, 36, 257.

60. Sharma, B.; Mandani, S.; Sarma, T. K.; J. Nanopart. Res. 2015, $17,1$.

61. Singh, P.; Roy, S.; Jaiswal, A.; J. Phys. Chem. C 2017, 121, 22914.

62. Zeng, J.; Zhang, Q.; Chein, J.; Xia, Y.; Nano Lett. 2010, 10, 30.

Submitted: November 11, 2020

Published online: February 9, 2021 